There may be some instances in which a staff grade doctor will wish to return to the main career ladder in psychiatry. If this is so, the doctor should obtain a registrar post in psychiatry before proceeding to senior registrar and consultant. This means of progression is necessary for manpower purposes.

College requirements and employing authorities

The Royal College of Psychiatrists' requirements for contractual arrangements for holders of staff grade posts in psychiatry should be made known to employing authorities including Regional Health Authorities, and District Health Authorities. The Regional Adviser should also be informed and job descriptions for staff grade posts should be seen by the Regional Adviser or Deputy before advertisement.

Approved by Council June 1989

\title{
Quarterly and Annual Meetings of the Royal College of Psychiatrists
}

Members are reminded that they may need to apply for study leave in advance of the College's Quarterly and Annual Meetings in order that their registration fees are re-imbursed. The daily registration fees are as follows: Inceptors and Retired Members: $£ 20$; Members and Non-Member Psychiatrists: £30; NonMembers: $£ 60$.

The provisional programmes for these meetings in 1989-1990 are as follows:

Autumn Quarterly Meeting 1989, 25 and 26 October 1989 at Kensington Town Hall, Hornton Street, London W8

Wednesday 25 October 1989: Computers in psychiatry, psychotherapy in the ederly, an up-date on problems with benzodiazepines, cognitive therapy, the young brain damaged, casualty psychiatry; The Maudsley Lecture will be given by $\operatorname{Dr}$ T. J. Crow and a lunch-time lecture by $\mathrm{Dr} \mathrm{K}$. Jamison.

Thursday, 26 October 1989: Biological markers in depression for the 90s, history of psychiatry, CPNs a rival service?, Quarterly Business Meeting, rape, and two short paper sessions.

Winter Quarterly Meeting 1990, Tuesday, 23 January and Wednesday 24 January 1990 at The Royal Society of Medicine, 1 Wimpole Street, London W1.

The Maudsley Bequest Lecturers will be Drs G. M. Goodwin, M. Abou-Saleh, T. R. E. Barnes, J. F. K. Deakin, J. Hamilton, S. Hollins, Professor N. Kreitman, Drs S. Lewis, R. Littlewood, M. Robertson, A. Ryle, E. Welldon and S. Wolkind. The Eli Lilly
Lecture will be given by George Winokur, MD, The Paul W. Penningroth Professor and Head, Department of Psychiatry, The University of Iowa, USA, on Tuesday, 23 January 1990 . The Blake Marsh Lecture will be given by Frank J. Menolascino, Professor and Chairman, University of Nebraska Medical Center, USA on Wednesday, 24 January 1990.

Spring Quarterly Meeting 1990, Tuesday, 10 April and Wednesday, 11 April 1990 at the University of Galway, Ireland

The scientific programme will include sessions on anxiety disorders, new clinical and legal issues in tardive dyskinesia, control of mental health, alcohol clinical studies, community care - evaluation, posttraumatic stress disorder, personality disorder, serotonin, child and adolescent psychiatry, family studies, and short paper sessions. Details of hotel accommodation and group travel will be available in due course.

Annual Meeting 1990, Tuesday, 10 July-Thursday, 12 July 1990 at the Birmingham Metropole Hotel, National Exhibition Centre, Birmingham

It is hoped that the scientific programme will include sessions on diagnostic issues of panic disorder, problems of overlap in depression, post-natal depression, in-patient psychotherapy, developmental psychiatry, forensic psychiatry, Birmingham alumnae, epilepsy in psychiatry, and short paper sessions. The Annual Dinner will be held on Tuesdy, 10 July 1990 at the Birmingham Metropole Hotel. 